\title{
Should we prescribe carbapenem for treating febrile urinary tract infection caused by extended-spectrum $\beta$-lactamase-producing Enterobacteriaceae in children with vesicoureteral reflux?
}

Ji Young Park, MD, PhD

Department of Pediatrics, Chung-Ang University Hospital, Chung-Ang University College of Medicine, Seoul, Korea

\section{Key message}

Recent studies are focused on the noninferiority of noncarbapenem therapy for the treatment of extended-spectrum $\beta$-lactamases producing Enterobacteriaceae infections to reduce the utilization of carbapenem.

Urinary tract infections (UTIs) are the most common serious bacterial infections in children. ${ }^{1)}$ The most common pathogens causing UTIs are Enterobacteriaceae, such as Escherichia coli and Klebsiella species. ${ }^{2)}$ Antimicrobial drug resistance to fluoroquinolone, cephalosporin, and carbapenem among Enterobacteriaceae has spread globally over the past few decades and become a pressing problem. ${ }^{3)}$ The dissemination of drug-resistant organisms is troublesome for clinicians when selecting empirical antibiotics. Patients with UTIs were historically administered broad-spectrum cephalosporin as the empirical therapy. Carbapenem is the definitive therapy for infections caused by extended-spectrum $\beta$ lactamases (ESBL)-producing bacteria. However, carbapenemsparing options are on the rise for mild infections with ESBL producers because its overuse is leading to the emergence of carbapenem-resistant organisms.

Recent studies have focused on the noninferiority of noncarbapenem therapy for the treatment of ESBL-producing Entero bacteriaceae infections to reduce carbapenem utilization. ${ }^{4-7)} \mathrm{A}$ review article examined noncarbapenem $\beta$-lactam (cephamycin, cefepime, piperacillin/tazobactam, and newer $\beta$-lactam/ $\beta$-lacta-

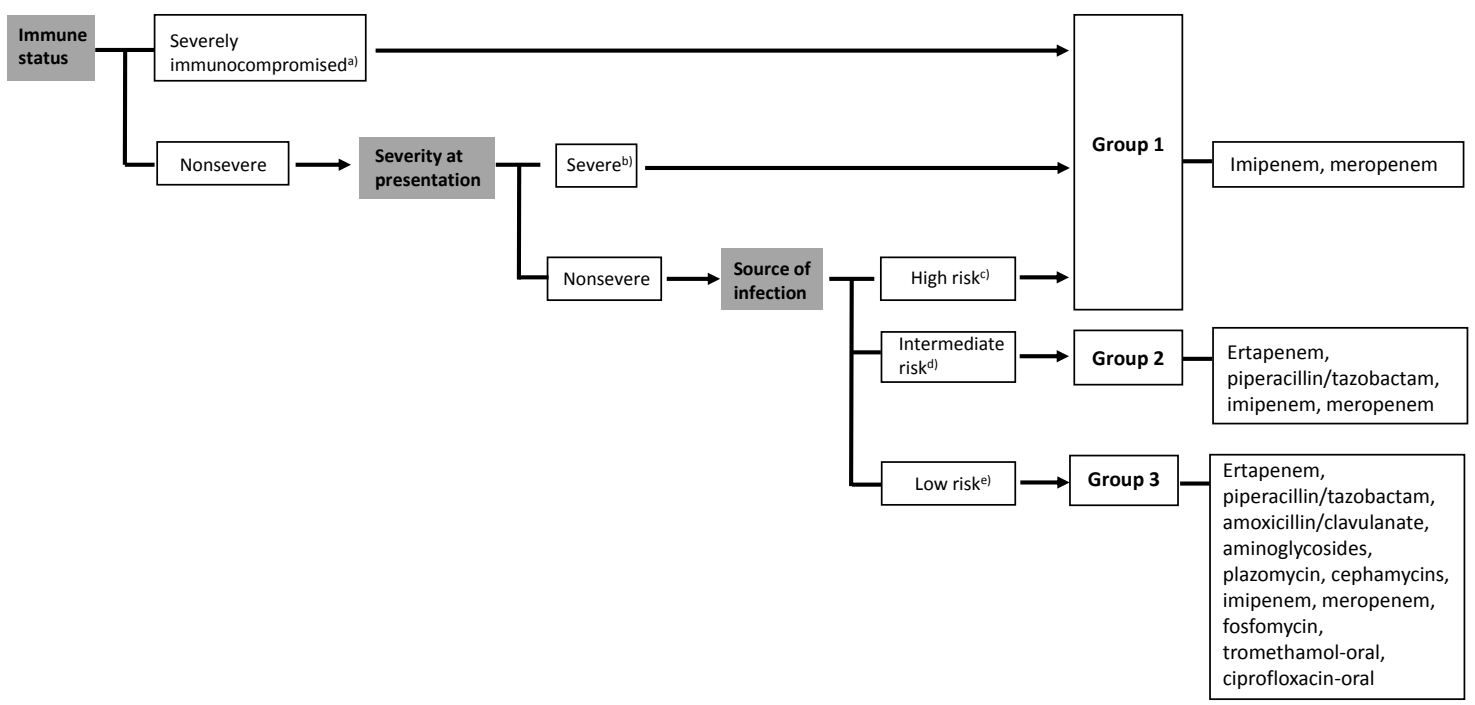

Fig. 1. Classification of patients according to immune status, severity at presentation, source of infection, and treatment options for infections caused by extended-spectrum $\beta$-lactamase-producing Enterobacteriaceae by group.) a) Severely immunocompromised: neutropenia $(<500 / \mu \mathrm{L})$, leukemia, lymphoma, HIV infection with $<200 \mathrm{CD} 4 / \mu \mathrm{L}$, solid organ or hematopoietic stem cell trans-

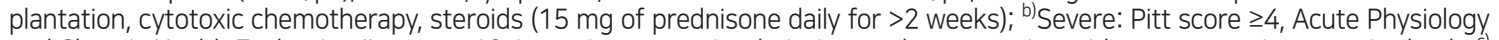
and Chronic Health Evaluation II score $>10$, intensive care unit admission, and presentation with severe sepsis or septic shock; ${ }^{c}$ High risk: high-inoculum infections, drainage impossible or inadequate (e.g., pneumonia, endocarditis, inadequately drained deep-



Corresponding author: Ji Young Park, MD, PhD, Division of Pediatric Infectious Diseases, Department of Pediatrics, Chung-Ang University Hospital, Chung-Ang University College of Medicine, 102 Heukseok-ro, Dongjak-gu, Seoul 06973, Korea

凶Email:jypark@caumc.or.kr, https://orcid.org/0000-0002-6777-0494

Received: 3 November, 2020, Revised: 16 December, 2020, Accepted: 28 December, 2020

This is an open-access article distributed under the terms of the Creative Commons Attribution Non-Commercial License (http://creativecommons.org/licenses/bync/4.0/) which permits unrestricted non-commercial use, distribution, and reproduction in any medium, provided the original work is properly cited.

Copyright (c) 2021 by The Korean Pediatric Society 
mase inhibitors) therapy for ESBL-producing bacterial infections. The authors suggested that noncarbapenem could be considered in patients with mild to moderate low-inoculum infections. ${ }^{6}$ A recent literature review summarized published articles regarding the treatment of ESBL-producing Enterobacteriaceae infections. Patients were divided into 3 groups: group 1, severe or nonsevere infections from high-risk sources and/or severely immunocompromised patients; group 2, nonsevere infections and intermediate-risk sources; and group 3, nonsevere infections and lowrisk sources (Fig. 1). They concluded that carbapenem should be the choice of drug for the treatment of ESBL-producing Entero bacteriaceae in severe infections, whereas other antimicrobial agents could be considered for mild infections such as UTIs. $\left.{ }^{7}\right)$ Thus, using noncarbapenem therapy for treating UTIs caused by ESBL-producing bacteria could be an effective way to prevent carbapenem overuse.

Furthermore, children with vesicoureteral reflux (VUR) are at high risk for acute and recurrent pyelonephritis. ${ }^{8)}$ In patients with VUR, it is unknown whether carbapenem therapy can reduce the short-term recurrence. Therefore, a prospective study is needed to compare the treatment outcomes of carbapenemtreated and non-carbapenem-treated patients diagnosed with UTIs due to ESBL producers underlying VUR. To enable a careful conclusion, large samples and multivariate analysis are required.

If UTIs caused by ESBL-producing bacteria are alleviated through empirical noncarbapenem therapy, switching to carbapenem therapy is a difficult decision for clinicians. To solve this challenge and develop management guidelines, additional largescale randomized controlled trials are required.

\section{Conflicts of Interest}

No potential conflicts of interest for this article are reported.
See the article "Febrile urinary tract infection in children: changes in epidemiology, etiology, and antibiotic resistance patterns over a decade" via https://doi.org/10.3345/cep.2020. 00773.

\section{References}

1. Lindsey K, Marianella H, John DS. The clinical diagnosis and management of urinary tract infections in children and adolescents. Paediatr Int Child Health 2017;37:273-9.

2. Zorc JJ, Kiddoo DA, Shaw KN. Diagnosis and management of pediatric urinary tract infections. Clin Microbiol Rev 2005;18:417-22.

3. Amy JM, Giswlw P, Johann DDP. The role of epidemic resistance plasmids and international high risk clones in the spread of multidrug-resistant Enterobacteriaceae. Clin Microbiol Rev 2015;28:565-91.

4. Lee B, Kang SY, Kang HM, Yang NR, Kang HG, Ha IS, et al. Outcome of antimicrobial therapy of pediatric urinary tract infections caused by extended-spectrum $\beta$-lactamase-producing Enterobacteriaceae. Infect Chemother 2013;45:415-21.

5. Yoshifusa A, Isil IE, Kunihiko F, Hitomi W, Yasuha O, Satoshi H, et al. Efficacy of non-carbapenem antibiotics for pediatric patients with first febrile urinary tract infection due to extended-spectrum beta-lactamaseproducing Escherichia coli. J Infect Chemother 2017;23:517-22.

6. Pranita DT, Jesus RB. The use of noncarbapenem $\beta$-lactams for the treatment of extended-spectrum $\beta$-lactamase infections. Clin Infect Dis 2017; 64:972-80.

7. Gutiérez-Gutiérrez B, Rodríguez-Bano J. Current options for the treatment of infections due to extended-spectrum beta-lactamase-producing Enterobacteriaceae in different groups of patients. Clin Microbiol Infect 2019;25:932-42.

8. Elder JS. Vesicoureteral reflux. In: Kliegman RM, Stanton BF, St. Geme JW III, Schor NF, Behrman RE, editors. Nelson textbook of pediatrics. 21st ed. Philadelphia (PA): Elsevier, 2019:2796-800.

How to cite this article: Park JY. Should we prescribe carbapenem for treating febrile urinary tract infection caused by extended-spectrum $\beta$-lactamase-producing Enterobacteriaceae in children with vesicoureteral reflux? Clin Exp Pediatr 2021; 64:284-5. https://doi.org/10.3345/cep.2020.01830. 